\title{
THE EFFECTS OF SWIMMING AND DRY-LAND RESISTANCE TRAINING PROGRAMME ON NON-SWIMMERS
}

\author{
JERZY SADOWSKI ${ }^{1}$, ANDRZEJ MASTALERZ², WILHELM GROMISZ ${ }^{3}$, \\ EWA JÓWKO ${ }^{4}$, MARIUSZ BUSZTA ${ }^{5}$ \\ Józef Piłsudski University of Physical Education in Warsaw, Faculty of Physical Education and Sport in \\ Biała Podlaska, Department of Athletics ${ }^{1}$, Department of Swimming and Water Safety, \\ Department of Physiology and Biochemistry ${ }^{4}$ Department of Foreign Languages ${ }^{5}$ \\ Józef Piłsudski University of Physical Education in Warsaw, Faculty of Physical Education, \\ Department of Biomechanics ${ }^{2}$
}
Mailing address: Jerzy Sadowski, Faculty of Physical Education and Sport, Department of Athletics, 2 Akademicka Street, 21-500 Biała Podlaska, tel.: +48 83 3428803, fax: +48 83 3428800, e-mail: jerzy.sadowski@awf-bp.edu.pl

\begin{abstract}
Introduction. The aim of the study was to estimate the influence of combined swimming and dry-land resistance training on swimming force, swimming performance and strength in non-swimmers. Material and methods. Thirty male non-swimmers took part in the research. They were randomly assigned to one of the two groups: experimental $(n=17)$ and control $(n=13)$. The experimental group took part in combined swimming and dry-land resistance training. The control group took part in swimming training only. The swimming and dry-land resistance training programme lasted twelve weeks (48 training sessions of swimming and 36 sessions of dry-land resistance training). Average training volume and intensity were the same for all swimmers throughout the study protocol. The training programme included dominant aerobic work in front crawl. Results. Dry-land resistance training applied in the experimental group significantly improved the upper body strength. In spite of the theory that dry-land strength training is probably not specific enough to improve the sprint swim performance, the experimental group tended to demonstrate greater improvement in sprint performance. The imitation of the underwater phase of shoulder work during front crawl provided by the ergometer can be a useful training method in non-swimmers.
\end{abstract}

Key words: swimming, ergometer, strength, tethered swimming, power

\section{Introduction}

Power represents the ability to perform movements at high speed, or the possibility of developing high strength in a short time. More than sixty years ago the relationship between power, strength and speed of muscle contraction was described by Hill [1]. Swimming performance is a multi-factorial phenomenon depending upon energetics, biomechanics, hydrodynamics, anthropometrics and strength parameters [2,3]. Strength and speed are major factors determining performance of swimmers [4].

Scientists and coaches agree that training should include sessions on land and in water. Many authors emphasise that the achievement of high results in swimming is not possible without special strength preparation $[5,6,7,8,9,10,11,12,13,14$, $15,16]$.

Strength and endurance training in swimming is administered both on land and in water. Activities on land constitute a component of training. During the year swimmers train between 100 and 300 hours per year. The time devoted to strength training, which is focused on the development of maximum strength and endurance, constitutes $60 \%$ of the total working time on land. The volume of work in water is about 1,000 hours per year, during which athletes cover from 1300 to $3400 \mathrm{~km} \mathrm{[10,}$ 11]. Several showed that the combination of strength and en- durance training inhibits strength and power development [17, $18,19]$. Some studies showed that concurrent training hinders the development of strength and power $[17,19]$, and endurance $[18,20]$. Other studies reported positive effects of dry-land resistance training on sprint performance in swimming [21, 22, 23]. However, Tanaka et al. [24] did not observe improvement in performance after a dry-land strength training period. These authors claimed that combined swimming and traditional dryland strength training did not enhance swimming performance, while combined swimming and swimming-specific in-water strength training increased swimming velocity. Tanaka et al. [24] also suggested that strength training executed in water would be more efficient than dry-land training. Nevertheless, the efficacy of dry-land, resisted and assisted sprint training methods in sprint performance is widely documented [23, 24, 25]. Strength training improves swimming performance [4, 25, 26, 27] and performance-related parameters such as increased stroke length [27], reduced stroke rate [25, 26] and increased tethered swimming force [4, 25, 26, 27]. Therefore, while improvement of swimming technique can be caused by strength training [12], it seems important to analyse the influence of specific land training on swimming performance in non-swimmers. Therefore, the aim of this work was to assess the effects of combined swimming and dry-land resistance training on swimming performance, force and strength in non-swimmers. 


\section{Methods}

\section{Subjects}

Thirty male non-swimmers (mean age $-20.8 \pm 0.9$ yrs, stature $-181 \pm 1.6 \mathrm{~cm}$, body mass $-73.7 \pm 3.4 \mathrm{~kg}$ ) took part in the research. They were randomly assigned to one of the two groups: experimental $(n=17)$ and control $(n=13)$. The experimental group took part in combined swimming and dry-land resistance training. The control group took part in swimming training only.

The subjects provided written informed consent to participate in this research, and the procedures were approved by the institutional review board.

\section{Training device}

The ergometer "Hydroisokinetic" [28] was applied during resistance training sessions (Fig. 1). The ergometer may provide an imitation of the underwater phase of shoulder work during front crawl. The ergometer has a base frame, made of stainless steel, with a screw mechanism mounted to the edge of the pool. During training, each of the subjects lay on a bench, assuming the body position as when swimming. The tested subject drove the ergometer holding the handles connected to the head equipped with blades with infinitely adjustable geometry (1). During the exercise the force and length of stroke motion of the right and left arm were measured. Two-component force transducer (3) was used to estimate force during control measurements and training sessions. The length of stroke was measured by potentiometer (2) located at the axis of the head rotation.

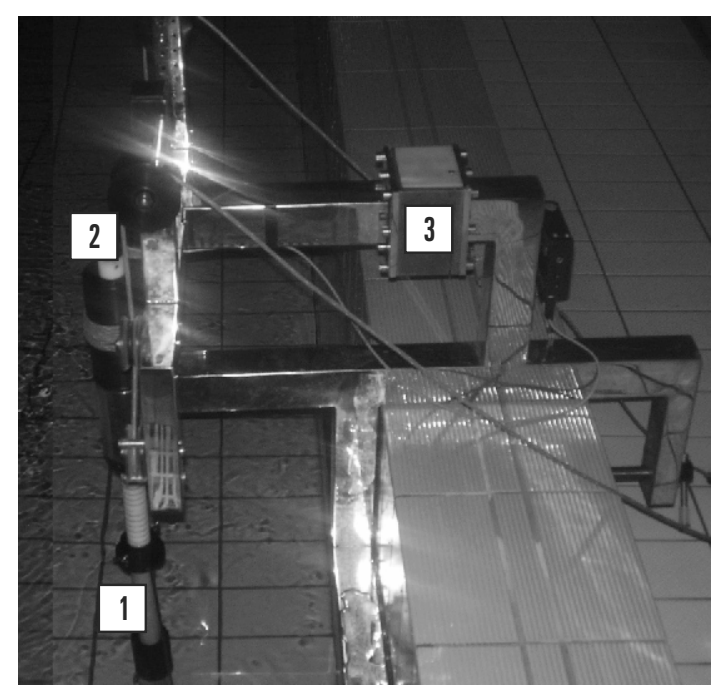

Figure 1. The ergometer used in the study

\section{Training procedure}

Swimming training was held four times a week (Monday, Tuesday, Wednesday and Thursday at 8.45 p.m.). It was carried out in a $25 \mathrm{~m}$ pool. Training was conducted according to the methodology described by Brems [29]. Before each training the swimmers carried out a warm-up of 10-20 minutes. The swimming training program lasted twelve weeks (48 training sessions). Average training volume and intensity were the same for all participants throughout the study protocol. Their training included dominant aerobic work in front crawl. Thorough analysis of swimming training is presented in Tables 1 and 2 .
Table 1. Characteristics of energy zones and their application in training (percentage shown in brackets)

\begin{tabular}{|c|c|c|c|c|c|}
\hline & $\begin{array}{c}\text { Aerobic 1* } \\
\text { REC }\end{array}$ & $\begin{array}{c}\text { Aerobic 2* } \\
\text { EN1 }\end{array}$ & $\begin{array}{c}\text { Mix 3* } \\
\text { EN2.3 }\end{array}$ & $\begin{array}{c}\text { Anaerobic 4* } \\
\text { SP1.2 }\end{array}$ & $\begin{array}{c}\text { Sprint 5*, } \\
\text { SP3 }\end{array}$ \\
\hline \multirow{2}{*}{ Distance $[\mathrm{m}]$} & 33600 & 22150 & 14000 & 2800 & 1825 \\
& $(45.18)$ & $(29.78)$ & $(18.82)$ & $(3.76)$ & $(2.45)$ \\
\hline
\end{tabular}

$1^{*}$ - aerobic recovery, $2^{*}$ - aerobic development, $3^{*}-$ mix aerobic anaerobic, 4 * anaerobic, $5^{*}-$ creatine phosphate.

Table 2. Training volume in relation to swimming techniques (percentage shown in brackets)

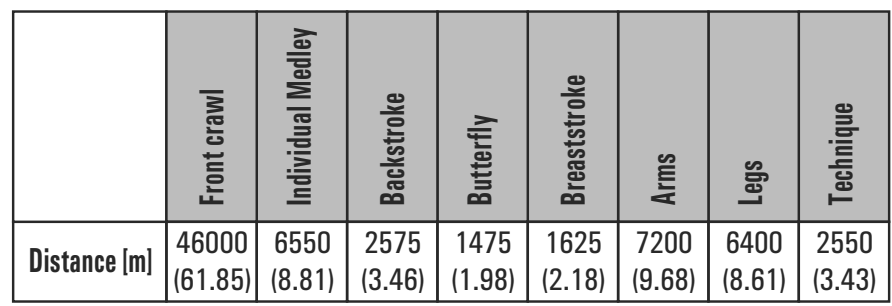

\section{Design of experimental training}

Resistance training programme on land with the use of the ergometer in the experimental group lasted twelve weeks (36 training sessions). Training was held three times a week (Monday, Wednesday, Friday). It was preceded by a 10-minute warmup and it consisted of 6 sets of 50 seconds of work and 10 -second rest intervals.

The results of swimmers at different sports levels show that the frequency of swimming cycles in start-up conditions is within 51-60 strokes/minute and it is the optimal frequency at which the length of cycle has the main influence on the sports result [12]. Therefore, during the training session focused on the development of power the frequency of motor cycles was observed. It was on the basis of the frequency of motor cycles that resistance was determined. It was assumed that if the limitation of movements using the ergometer exceeds 60 strokes/minute, the applied resistance is ineffective. To increase the intensity of exercise, the size of blades in water was adjusted to provide effective resistance.

\section{Test procedures}

Control measurements were conducted before the start (pretest) of the experiment and after 12 weeks of combined swimming and dry-land resistance training (posttest). Measurements included:

- assessment of isometric strength(IS),

- assessment of swimming performance during $25 \mathrm{~m}$ (V25) and $75 \mathrm{~m}$ (V75) front crawl swim by the upper extremities drive (from a push-off start in the water),

- $\quad$ assessment of strength during tethered swimming(TS).

Both experimental and control groups were evaluated at the same moments. The evaluations were conducted during one week in each evaluation moment.

The measurement of isometric strength (IS) was conducted on the ergometer (Fig. 1). Two five-second measurements of shoulder flexion with arms adjusted at the position of $45^{\circ}$ between arms and trunk were done. The greatest value of IS was chosen for the analysis. Also, strength in a 30 -second test was measured (ISE). In that protocol strength at the end of the test was assessed, which was an indicator of endurance. The signals were captured by computer interface and stored in a data acquisition programme at $400 \mathrm{~Hz}$. 
One day after IS test, the swimmers performed $25 \mathrm{~m}$ and $75 \mathrm{~m}$ front crawl time trials. Stroke length and stroke frequency were determined for each $25 \mathrm{~m}$ lap with a camera.

A minimum of 3 complete stroke cycles were analyzed during the $25 \mathrm{~m}$ swim as well as during each $25 \mathrm{~m}$ of the $75 \mathrm{~m}$ swim over a distance of $10 \mathrm{~m}$, which corresponded to the field of the camera. The camera was placed $12.5 \mathrm{~m}$ from the edge of the pool and the recording started $7.5 \mathrm{~m}$ after the departure and lasted until $17.5 \mathrm{~m}$ of each $25 \mathrm{~m}$. Speed of locomotion was defined as a product of stroke rate SR and distance per stroke SD and could be defined through the time of stroke cycle T:

$$
\mathrm{V}=\frac{\mathrm{SD}}{\mathrm{T}}=\frac{\mathrm{SD} \cdot \mathrm{SR}}{60}
$$

Equation (1) can be rewritten for the distance per stroke SD:

$$
\mathrm{SD}=\mathrm{V} \cdot \mathrm{T}=\frac{60 \cdot \mathrm{V}}{\mathrm{SR}}
$$

Tethered swimming force was defined by two incremental tests with swimmers connected to a $1000 \mathrm{~N}$ load cell with 4 attached strain gauges by a commercial elastic cord (StrechCordz Long Belt Slider (12-31 lb), NZ Manufacturing INC, USA). Strength was evaluated during 10-second (TS10) and 30-second (TS30) tests. The signals were sampled at frequency of $400 \mathrm{~Hz}$ and stored in a data acquisition programme at $400 \mathrm{~Hz}$.

\section{Statistical analyses}

Normality of distribution was checked with the Shapiro-Wilk test (StatSoft, Inc. (2007). STATISTICA - data analysis software system, version 8.0. www.statsoft.com.) and non-normal distribution was found. All differences between groups were calculated with the use of the Mann-Whitney test, and within-group differences between pre- and post-training were estimated by the Wilcoxon test.

\section{Results}

\section{Strength performance}

Figure 2 presents the values of isometric force obtained during the shoulder flexion on the ergometer, for the experimental and the control group in two evaluation moments.

Force during shoulder flexion determined during IS test significantly increased by $6.91 \%(\mathrm{p}<0.05)$ between pretest and posttest in the experimental group. After twelve weeks of dryland resistance training the experimental group demonstrated higher values than the control group in ISE test (1.72\%). The experimental group increased ISE strength from pretest to posttest by $32.03 \%(p<0.001)$, whereas the increase in the control group was not statistically significant $(5.20 \%$, p > 0.05). No differences were observed between the experimental and the control group.

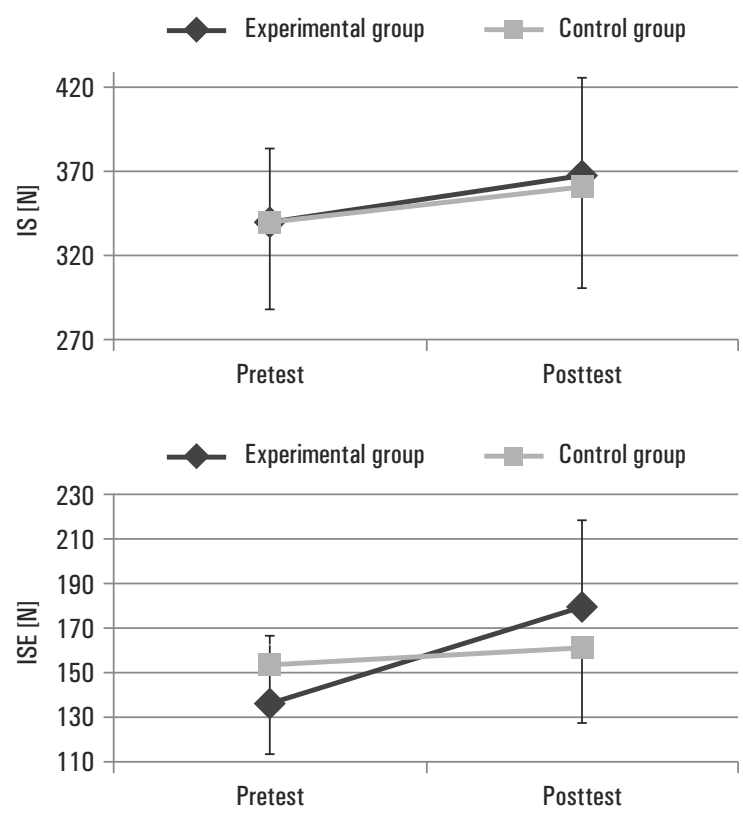

Figure 2. Values of shoulder strength during two isometric tests IS and ISE determined for the experimental and the control group in two evaluation moments

\section{Swimming performance}

Figure 3 presents swimming performance in $25 \mathrm{~m}$ and $75 \mathrm{~m}$ front crawl, at the beginning of the protocol (pretest) and after twelve weeks of training (posttest).

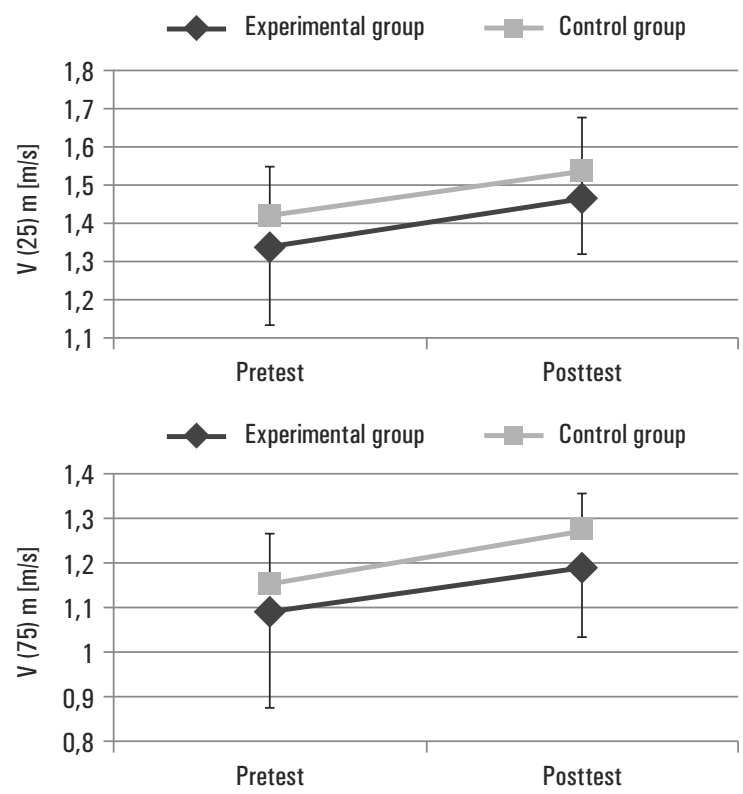

Figure 3. Swimming performance in $25 \mathrm{~m}$ and $75 \mathrm{~m}$ front crawl at the beginning of the protocol (pretest) and after twelve weeks of training (posttest) for the experimental group and the control group 
No differences were noted between the experimental and the control group. The experimental group tended to demonstrate bigger improvement in sprint performance. Regarding the $25 \mathrm{~m}$ test, the experimental group increased the performance from pretest to posttest by $9.55 \%(p<0.001)$ and the increase in per-formance was also observed from pretest to posttest $(7.95 \%, p<0.05)$ in the control group. Regarding the $75 \mathrm{~m}$ test, the experimental group increased the performance from pretest to posttest by $9.26 \%(\mathrm{p}<0.001)$, and the increase in performance was found from pretest to posttest $(7.96 \%$, $\mathrm{p}<0.05$ ) in the control group.

The data for stroke frequency and stroke distance during swimming performance in $25 \mathrm{~m}$ front crawl for two groups are presented in Figure 4. Stroke frequency insignificantly decreased $(-0.55 \%, p>0.05)$ in the experimental group and increased $(6.68 \%, \mathrm{p}>0.05)$ in the control group. The distance per stroke significantly increased in the experimental group $(9.66 \%$, $\mathrm{p}<0.05$ ) and insignificantly increased in the control group $(3.33 \%, \mathrm{p}>0.05)$.

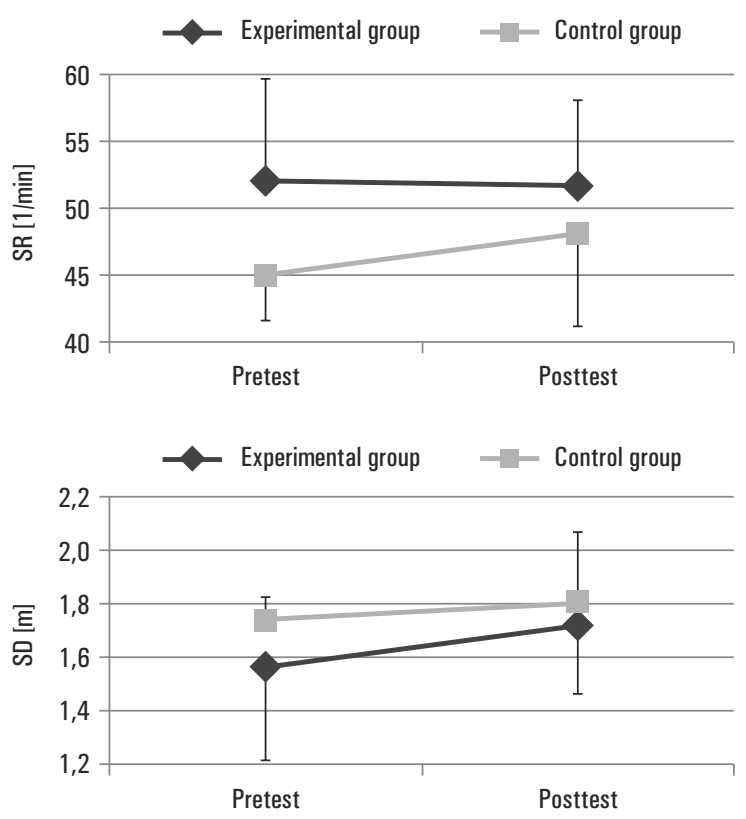

Figure 4. Mean and standard deviation values for stroke frequency and distance per stoke in $25 \mathrm{~m}$ front crawl at the beginning of the protocol (pretest) and after twelve weeks of training (posttest) for the experimental group and the control group

There were no differences between groups with regard to stroke frequency and distance per stoke in every $25 \mathrm{~m}$ of $75 \mathrm{~m}$ front crawl covered in the pretest and posttest (Tab. 3). A significant change $(8.22 \%, \mathrm{p}<0.05)$ for the last stroke distance (SD3) was observed in the experimental group and for SD2 $(9.36 \%, p<0.05)$ in the control group.

\section{Strength and endurance in tethered swimming}

Significant improvement of tethered swimming force was found in both tests for the experimental group (16.71\%, $<<0.001$ and $14.66 \%, \mathrm{p}<0.001$ for TS10 and TS30, respectively) as well as in the control group $(9.31 \%, p<0.05$ and $9.30 \%, p<0.05$ for TS10 and TS30, respectively). In addition, tethered swimming force was similar in the control and experimental groups at pretest and posttest ( $\mathrm{p}>0.05)$.
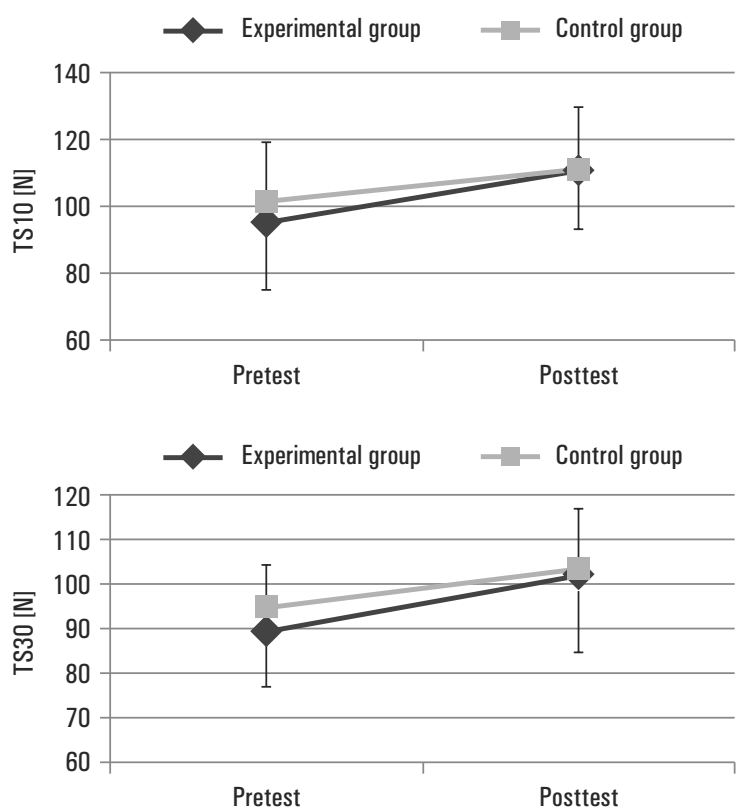

Figure 5. Tethered swimming force during 10-second (TS10) and 30-second (TS30) incremental swimming tests at the beginning of the protocol (pretest) and after twelve weeks of training (posttest) for the experimental and the control group

\section{Discussion}

It was hypothesised that combined swimming and dry-land resistance training would improve swimming force, swimming performance and strength in non-swimmers. In some articles traditional dry-land strength training or combined swimming and strength training did not appear to enhance swimming performance in untrained individuals or competitive swimmers [30]. It was observed that although combined training increased upper body strength, it did not produce faster sprint times compared with swimming training only [24]. Additionally, Bulgakova et al. [31] reported that in-water strength training was more effective than dry-land strength training. Our results are in line with the study by Aspenes et al. [32]. The improvement of dry-land strength occurred as expected in the experimental group. However, the control group also improved land force. Nevertheless, force during IS test increased significantly by

Table 3. Mean and standard deviation values for stroke frequency and distance per stoke in every $25 \mathrm{~m}(1,2,3)$ of $75 \mathrm{~m}$ front crawl at the beginning of the protocol (pretest) and after twelve weeks of training (posttest) for the experimental and the control group

\begin{tabular}{|l|c|c|c|c|c|c|c|}
\hline & & SR1 [cycles $/ \mathrm{min}]$ & SD1 $[\mathrm{m}]$ & SR2 [cycles $/ \mathrm{min}]$ & SD2 $[\mathrm{m}$ & SR3 [cycles/min] & SD3 [m] \\
\hline \multirow{2}{*}{ Exerimental } & Pretest & $41.5 \pm 7.2$ & $1.8 \pm 0.2$ & $40.9 \pm 7.2$ & $1.6 \pm 0.2$ & $39.4 \pm 8.6$ & $1.5 \pm 0.3$ \\
\cline { 2 - 8 } & Posttest & $45.4 \pm 7.2$ & $1.8 \pm 0.2$ & $42.2 \pm 6.8$ & $1.6 \pm 0.2$ & $41 \pm 6.8$ & $1.7 \pm 0.2$ \\
\hline \multirow{2}{*}{ Control } & Pretest & $44.1 \pm 5.6$ & $1.9 \pm 0.2$ & $42.5 \pm 4.7$ & $1.6 \pm 0.3$ & $42.6 \pm 4.5$ & $1.5 \pm 0.3$ \\
\cline { 2 - 8 } & Posttest & $45.3 \pm 2.3$ & $1.8 \pm 0.1$ & $43.4 \pm 2.3$ & $1.7 \pm 0.1$ & $43.9 \pm 2.3$ & $1.6 \pm 0.1$ \\
\hline
\end{tabular}


$6.91 \%(\mathrm{p}<0.05)$ and for ISE strength by $32.03 \%(\mathrm{p}<0.001)$ in the experimental group only, while force increase in the control group was insignificant. The improvement of tethered swimming force was as expected, and in line with the study by Girold et al. [25]. Significant improvement of tethered swimming force was observed in both tests for both the experimental group and the control group.

In spite of the theory that dry-land strength training is probably not specific enough to improve the sprint swim performance, in this research the experimental group tended to demonstrate bigger improvement in sprint performance (Fig. 3). However, stroke frequency decreased insignificantly $(-0.55 \%$, $\mathrm{p}>0.05)$ in the experimental group and increased insignificantly $(6.68 \%, p>0.05)$ in the control group. It may stem from the fact that swim-specific frequencies during dry-land resistance training differed too much from the movement pattern in water $[33,34]$. Specific dry-land resistance training applied in the research influenced the distance per stroke. The distance per stroke significantly increased in the experimental group $(9.66 \%, p<0.05)$ and insignificantly increased in the control group (3.33\%, p>0.05). Therefore, it is also possible that improvement in sprint swimming performance resulted from the distance per stroke influence. Several studies have shown a strong correlation between upper body strength and sprint swimming performance over $25 \mathrm{~m}$ and $50 \mathrm{~m}$ [35, 36, 37]. Training applied in the experimental group significantly improved upper body strength. It should be emphasised that differences between groups regarding upper body strength and sprint swimming performances were almost identical. Therefore, the differences in sprint swimming performance between both groups can also be explained by land strength and tethered swimming force improvement. Swimming performance improvement depends on the specificity of methods applied in training $[21,30,38]$ and training intensity [39, 40]. In the present study, dry-land resistance training programme was designed to resemble work in water conditions. The imitation of the underwater phase of shoulder work during front crawl provided by the ergometer can be a useful training method in non-swimmers.

The limitation of our study was that participants were male college-aged students. Future research should be carried out on competitive swimmers.

\section{Acknowledgments}

The research was accomplished within the framework of the Youth Activity project of Józef Piłsudski University of Physical Education in Warsaw, Faculty of Physical Education and Sport in Biała Podlaska, - MN. I/2 - financed by the Ministry of Science and Higher Education.

\section{Literature}

1. Hill A.V. (1938). The heat of shortening and the dynamic constants of muscle. Proceedings of the Royal Society of London $B$ 126(843), 136-195.

2. Barbosa T.M., Fernandes R.J., Keskinen K.L., Vilas-Boas J.P. (2008). The influence of stroke mechanics into energy cost of elite swimmers. European Journal of Applied Physiology 103(2), 139-49.

3. Barbosa T.M., Bragada J.A., Reis V.M., Marinho D.A., Carvalho C., Silva A.J. (2010). Energetics and biomechanics as determining factors of swimming performance: updating the state of the art. Journal of Science and Medicine in Sport 13(2), 262-9.

4. Trappe S., Pearson D.R. (1994). Effects of weight assisted dry- land strength training on swimming performance. Journal of Strength and Conditioning Research 8, 209-213.

5. Strzelczyk R., Jurecki G. (1976). The influence of experimental loads on speed growth in front crawl. Poznań: AWF Poznań. [in Polish]

6. Strzelczyk R., Wachowski E. (1994). Propulsive force in swimming. Trening 3, 5-17. [in Polish]

7. Jurecki G. (1978). Analysis of special strength levels in a training cycle of swimmers. Poznań: AWF Poznań. [in Polish]

8. Vajciehovskij S.M. (1985). Sistiema sportivnoj podgatovki plavcov k Olimpijskim igram. Moskwa.

9. Counsilman J.E. (1994). The new science of swimming. New Jersey: Prentice-Hall.

10. Płatonow W.N. (1997). Professional swimming training. Warszawa: RCMSKFiS. [in Polish]

11. Płatonow W.N. (2000). Obszaja tieoria podgatowki sportsmienaw w ołimpijskom sportie, Kijew: Olimpijskaja Litieratura.

12. Maglischo E.W. (2003). Swimming fastest. The essential reference on technique, training and program design. Champaign, Illinois: Human Kinetics Publishers.

13. Sweetenham B., Atkinson J. (2003). Championship swim training. Champaign, Illinois: Human Kinetics Publishers.

14. Hanula D., Thornton N. (2001). The swim coaching bible. Champaign, Illinois: Human Kinetics Publishers.

15. Hanula D. (2003). Coaching swimming successfully. Champaign, Illinois: Human Kinetics Publishers.

16. Colwin M.C. (2002). Breakthrough swimming. Champaign, Illinois: Human Kinetics Publishers.

17. Dudley G.A., Djamil R. (1985). Incompatibility of enduranceand strength-training modes of exercise. Journal of Applied Physiology 59, 1446-1451.

18 Abernethy P., Quigley B. (1993). Concurrent strength and endurance training of the elbow extensors. Journal of Strength and Conditioning Research 7(7), 234-240.

19. Hennessey L.C., Watson A.W.S. (1994). The interference effects of training for strength and endurance simultaneously. Journal of Strength and Conditioning Research 8(1), 12-19.

20. Sale D.G., MacDougall J.D., Jacobs I., Garner S. (1990). Interaction between concurrent strength and endurance training. Journal of Applied Physiology 68, 260-270.

21. Costill D.L. (1999). Training adaptations for optimal performance. In K.L. Keskinen, P.V. Komi, A.P Hollander (eds), Biomechanics and medicine in swimming VIII (pp. 381-390). Jyvaskyla: University of Jyvaskyla.

22. Pichon F., Chatard J.C., Martin A., Cometti G. (1995). Electrical stimulation and swimming performance. Medicine and Science in Sports and Exercise 27, 1671-1676.

23. Strass D. (1988). Effects of maximal strength training on sprint performance of competitive swimmers. In B.E. Ungerechts, K. Wilke, K. Reischle (eds), Swimming Science V (pp. 149-156). London: Spon Press.

24. Tanaka H., Costill D.L., Thomas R., Fink W.J., Widrick J.J. (1993). Dry-land resistance training for competitive swimming. Medicine and Science in Sports and Exercise 25, 952-959.

25. Girold S., Maurin D., Dugue B., Chatard J.C., Millet G. (2007). Effects of dry-land vs. resisted-and assisted-sprint exercises on swimming sprint performances. Journal of Strength and ConditioningResearch 21, 599-605.

26. Girold S., Calmels P., Maurin D., Milhau N., Chatard J.C. (2006). Assisted and resisted sprint training in swimming. Journal of Strength and Conditioning Research 20, 547-554.

27. Toussaint H.M., Vervoorn K. (1990). Effects of specific high resistance training in the water on competitive swimmers. International Journal of Sports Medicine 11, 228-233.

28. Sadowski J., Gromisz W., Ivančenko E.I. (2005). The use of " $\mathrm{Hy}$ droisokinetic 1" in the training of swimmers. Swimming - III, Research, Training, Hydrorehabilitation (pp. 49-53). SanktPetersburg. 
29. Brems M. (1984). The fit swimmer: 120 workouts and training tips. Chicago, Illinois: Contemporary Books.

30. Tanaka H., Swensen T. (1998). Impact of resistance training on endurance performance. A new form of cross training? Sports Medicine 25, 191-200.

31. Bulgakova N.Z., Vorontsov A.R., Fomichenko T.G. (1990). Improving the technical preparedness of young swimmers by using strength training. Soviet Sports Review 25(2), 102104.

32. Aspenes S., Kjendlie P., Hoff J., Helgerud J. (2009). Combined strength and endurance training in competitive swimmers. Journal of Sports Science and Medicine 8, 357-365.

33. Bollens E., Annemans L., Vaes W., Clarys J.P. (1988). Peripheral EMG comparison between fully tethered swimming and free front crawl swimming. In B. Ungerechts, K. Wilke, K. Reischle (eds), Swimming science 5 (pp. 173-181). Champaign, Illinois: Human Kinetics Publishers.

34. Toussaint H.M., Beelen A., Rodenburg A., Sargeant A.J., de Groot G., Hollander A.P., et al. (1988). Propelling efficiency of front crawl swimming. Journal of Applied Physiology 65, 2506-2512.

35. Sharp R., Troup J.P., Costill D.L. (1982). Relationship between power and sprint freestyle swimming. Medicine and Science in Sports and Exercise 14, 53-56.
36. Hawley J.A., Williams M.M., Vickovic M.M., Handcock P.J. (1992). Muscle power predicts freestyle swimming performances. British Journal of Sports Medicine 26(3), 151-155.

37. Smith D.J., Norris S.R., Hogg J.M. (2000). Performance evaluation of swimmers: Scientific tools. Sports Medicine 32, 539554.

38. Stewart A.M., Hopkins W.G. (2000). Seasonal training and performance of competitive swimmers. Journal of Sports Sciences $18,873-884$.

39. Mujika I., Chatard J.C, Busso T., Geyssant A., Barale F., Lacoste L. (1995). Effects of training on performance in competitive swimming. Canadian Journal of Applied Physiology 20(4), 395-406.

40. Chatard J.C., Mujika I. (1999). Training load and performance in swimming. In K.L. Keskinen, P.V. Komi, A.P. Hollander (eds), Biomechanics and medicine in swimming VIII (pp. 429-434). Finland: University of Jyvaskyla.

Submitted: March 3, 2014

Accepted: February 13, 2015 